\title{
Blogland, bogland
}

\author{
S. Berner \\ sberner@ecognus.com
}

'I think the Web makes me not alone and I feed it my intimacies, and the Web is my constant connection to something larger than myself ... ' John Hall, world's first blogger

This is not a journey through the land of Web logs, because such a journey is as impossible at the moment as any one through a particular cyberland. There are too many of them (112 million by December 2007 according to Technorati), they are too various, and much of the content is utterly useless. But just because a school magazine and the New York Times are both deemed 'journalism', it does not necessarily follow that we should stop reading papers. It just means that we need to be discerning.

To be discerning, we need a road map to travel along. Unfortunately, I have not come across one useful road map thus far, so my journey is at best haphazard and at worst chaotic. I dip in and out of people's blogs, bookmark a few, respond to a few, promise myself that I will come back and 'engage' with this or that person, and lose them in the process of searching others.

Writing about blogs is as ambiguous as finding and reading them. Six months ago, I wanted to put something together for a workshop on using blogs for marketing, and after much effort, found two books that were next to useless, so I will not even mention their titles. There were quite a few books on the technical aspects of hosting, coding, implementing third-party software, etc. and a few on the legal aspects of blogging, in which lawyers wagged their forefingers warning against disclosure, defamation, industrial espionage and all the other niceties that come attached to the notion of 'freedom of speech'.

By January this year, there were 10 books dealing with the different aspects of blogging at my university, and tens of thousands of academic papers written about the phenomenon, its uses and abuses, its benefits and detractions. It was time I started taking this phenomenon seriously enough to write something about it, but not with too much aplomb. One does not need to be reminded that fads are the characteristic of the cyber-age, from e-mail as a social engineering tool, passing through paperless offices, and knowledge management which was going to see us all heaped in the corridor next to the water cooler sharing our wisdom, to Facebook as the best advertising and market research tool in the world. Blogs fall in between somewhere, as they can communicate information, be used instead of paper diaries, function as knowledge distribution and collaboration tools, and be used in marketing, market research, selling, finding the best car, watch and partner, make you coffee and iron your shirt ... OK, I am exaggerating, but the reader gets my point.

Blogs started when a vanguard of 'geeks' and 'nerds' decided to introduce some sense into the Internet that was already running out of control. They did similar things to what librarians do to promote specific items in their huge collections: write about them; point them out so that the readers do not have to depend on serendipity. The first log, apparently, was started in 1994 (http://www.links.net/vita/web/original.html) by Justin Hall, who was then a student at Swarthmore College in Pennsylvania and who finally dropped out of blogging in 2005, after one year of documenting his life online (Hermanci 2005), having apparently lost faith in 
the Internet as a medium for intimacy. In 1996 the medium, with which we are currently most familiar, began and involved the regular posting of items in reverse chronological order on a Webpage (Blood 2000). In 1999, Bridget Eaton defined a Blog as a Website with dated entries, the newest being at the top, and the first build-your-own-Weblog tool was launched by Pitas (http://www.pitas.com), resulting in a blog explosion. Blogger and the rest followed. In less than six years, blogs have developed into highly sophisticated e-publishing software that permits the user to upload streaming media, link to a slide show of their photos on Flickr, provide RSS feeds to readers and write in different languages. Many Website hosting services now include blogging software in their packages.

Today, blogs are a natural by-product of a highly literate culture, exhibitionist streak, good business sense and CMS software all put together. In its 'cut-down version', a blog is a personal Website managed by an individual who compiles lists of links to personally interesting material interspersed with information and an editorial. It enables the user to instantly place their words and thoughts onto their own Weblog site. It also gives others the option of interacting with the user's blog via comments, thus initiating dialogue. This same option leaves the blogger wide open to abuse, as the case of Kathy Sierra has proven (Wagner 2007).

Their power lies in the fact that anyone and everyone with access to the Internet can now be in the public domain. Many writers in undemocratic countries use blogs for political activism and agitation as well to let the world know what is happening. A bestseller, We Are Iran, was compiled by Nasrin Alavi from blogs written in Persian by dissenting voices in Iran - a healthy 64000 blogs in Farsi at the time of publication in 2005. A 24-year-old Baghdadi woman began blogging about the war in her native Iraq in April 2003, under the title Baghdad burning, and her blog was published in 2005 under the same title. Bloggers are routinely arrested in Egypt for their writings: Ala Abdel Fatah (http://manalaa.net/) Rami Siyyam (http://ayoubelmasry.blogspot.com/) are of the few who have been detained in just the past six months.

But blogging is not limited to activism, although any kind of writing has the potential of being subversive. There is a book about book, and a book about guys, both 'lifted' off blogs. The wonderful collection of book illuminations and illustrations on the Bibliodyssey blog (http://bibliodyssey.blogspot.com/) was published in a handsome folio in late 2007. The author, Paul, is a medical scientist who has been running the blog since 2005 as an account of visual materia obscura, and his summaries provide the often fascinating and rich histories behind the astounding illustrations. Illustrations are 'a kind of bait to learning' (Levinson 2008).

I hope they serve beer in hell is an autobiography of a 'typical' US young male, involving drinking, hooking and making a fool of himself (Ouzounian 2006). The book was initially a blog (http://www.tuckermax.com/). The book was on the New York Times best seller list two years in a row, and sold over 30000 copies proving that when young males find something they are interested in, they do read (St. John 2006).

Who blogs? Although Weblogs are defined primarily as personal e-spaces, a few hours online will show that there are corporate blogs, small-business blogs, communities of practice blogs, blogs belonging to museums, to NGOs, to journalists, librarians, project managers, customer relation managers, evangelical pastors, Muslim preachers, political dissenters and teachers in primary, secondary and tertiary education. Some blogs even cause diplomatic dramas, such as that of the UN envoy to Sudan, Jan Pronk

(http://www.janpronk.nl/weblog.html) who was expelled from the country because he 'openly criticized Khartoum as well as rebel groups on his Web log.' 
Blogs vary in looks, feel and size. There are artlogs, photoblogs, sketchblogs, vlogs, music blogs using MP3, podcasting blogs and others that are part of a wider network of social media. 'Micro-blogging' is another type of blogging, which consists of blogs with very short posts. These can now be sent via Twitter (http://www.twitter.com/), which allows users to send 'updates' (or 'tweets'; text-based posts up to 140 characters long) to the Twitter Website, via short message service, instant messaging, or a third-party application such as Twitterrific software for Mac. For an obsessive writer like me, this is a parody of what serious blogging should be about, akin to a starvation diet.

I started thinking of using a Weblog for publishing in 2001, but somehow never got to do it. Then in 2004, I signed up with 20six.co.uk (www.20six.co.uk), and became very involved with a number of writer's there. I stopped for a few months, and when I came back I discovered that their administration had imposed fees and locked everyone's account until they paid. Fortunately, there was Google cache, so I was able to retrieve most of my writings through the search engine. The experience left me disenchanted for a year. Then more and more of my colleagues started boasting blogs, businesses started blogging and I decided I did not want to be left behind. On the recommendation of a friend, I moved to Blogger (www.blogger.com) in early 2006. One of my blogs deals with my work as a linguist. It is public and advertised on all my other Web presences. One is personal, written under a nom de plum, and linked to my third one which publishes translations into Arabic of works considered too controversial to appear anywhere in that part of the world.

Why do people blog? There are as many reasons as there are people. I would assume that the main drive would be having something to say, an opinion to share with others. But I come across an incredible amount of blogs that are pure drivel, full of complaints about the cat doing it on the carpet, the craving for chocolate while dieting, breaking up with one's partner, burning the paste, and so on. I might try to explain this by the fact that Generation Y is more comfortable with a digital toy than with a paper diary, and that humanity has been keeping diaries for as long as they have been writing, so it is the medium that has changed, and not the content.

Businesses use blogs for marketing - news about products, engaging with clients, bringing in repeat visitors to their Websites, and to score higher on search engines. In academic settings, blogs can be used to engage with students, practise analytical writing, peer reviews (in which aspect it is not much different from Wiki) and keeping track of progress. Blogs are great journalistic tools, too, allowing many 'indy' institutions to publish what would not have passed muster in mainstream media - the other side of the coin being that all kinds of 'conspiracy theorists' are also blogging full on, and the popularity of a blog in no way proves its credibility. In research done by the Air Force Office of Scientific Research, a query was run on Technorati (2007)(http://technorati.com/pop/blogs/) on the Gospel of Judas and sorted by an authority (the credibility of a site being a function of its incoming links, with an important post having many in-links and an unimportant post having only a few. High quality posts are valued by the number and quality of documents linking to it.). Quoting:

'The top result for the query [gospel of judas] was a post by one "Zeus Bhagwan" on the "citizen journalism" site News is Now Public7. The entire site had 877 inlinks, but there were no trackbacks for this particular post. In his profile on nowpublic.com, Zeus Bhagwan describes himself as follows : Zeus Bhagwan is the Prophet of 21st Century and reincarnation of God Zeus, god Jupiter, god Indra in 21st Century. This post was his only pronouncement on the subject, and in fact, his only post ever. Contrast Zeus Bhagwan's record with Prof. James R. Davila of the University of St. Andrews, Scotland, whose blog PaleoJudaica had only 128 inlinks at the time. Prof. Davila has a PhD in Near Eastern Studies from Harvard and has published at least 3 books and over 20 
peer-reviewed articles on early Christian writings and early rabbinic Judaism. Prof. Davila has published 61 posts on the topic of the Gospel of Judas alone. By ordinary measures, Davila would seem to be the more credible commentator; but, considering only blog inlinks, Zeus Bhagwan is $140 \%$ more authoritative than Davila' (Ulicny, Baclawski and Magnus 2007).

Personally, I blog for two main reasons - the first is marketing and the second is political. In my field of work, clients often want to see my style and language abilities prior to signing a contract, and the official blog is a good, free tool for airing my knowledge about my subject matter. The second blog is aimed at raising awareness among a particular segment of population in regards to particular issues about which they are not able to obtain information in their language easily due to political censorship. In a way, both blogs are also about knowledge sharing. Since I am chronically short of time, the blogs are not as functional as they could be.

What yet needs to be thoroughly researched is the readership. It is all fine and well to have all these millions of diaries fluttering on and off the LCD screens, but do we really know who reads them? Are they going to replace journalism as we have grown to know it? Will academics and novelists publish their work on blogs? And will blogs eventually morph into personal Websites, or will they remain a separate genre?

Time will show. And when I know, I will blog about it.

\section{References}

Alavi, N. 2005. We are Iran. New York: Soft Skull Press, Inc.

Blood, R. 2000. Weblogs: a history and perspective [Online]. Available WWW: http://www.rebeccablood.net/essays/weblog_history.html.

Hermanci, R. 2005. Time to get a life - pioneer blogger Justin Hall bows out at 31. San Francisco Chronicle 20.02.2005 [Online]. Available WWW: http://www.sfgate.com/cgibin/article.cgi?file=/c/a/2005/02/20/MNGBKBEJO01.DTL.

Levinson, G. 2008. The origins of our communication. [Online]. Available WWW: http://isgreaterthan.net/2008/01/21/the-origins-of-our-communication-bibliodysseys-paul-k/.

Ouzounian, G. (Tucker Max) 2006. I hope they serve beer in hell. New York: Citadel Press.

PK. 2007. Bibliodussey. London: Fuel.

Riverbend. 2005. Baghdad burning: girl blog from Iraq. New York: Feminist Press.

St. John, M. 2006. Dude, here’s my book. New York Times 16.04.2006 [Online]. Available WWW: http://www.nytimes.com/2006/04/16/fashion/sundaystyles/16CADS.html? pagewanted $=1 \&$ ei $=$ 5090\&en=778087aa367d0620\&ex $=1302840000 \&$ partner $=$ rssuserland $\& e m c=$ rss\&adxnnlx=1202295991-56ArGklR\%20enE6T58ocPSAA.

Technorati. 2007. Welcome to Technorati. [Online]. Available www: http://technorati.com/about/.

Ulicny, B., Baclawski, K. and Magnus, A. 2007. New metrics for blog mining. Proceedings of SPIE, Volume 6570 Data mining, intrusion detection, information assurance, and data 
networks security.

Dasarathy, B.V. (ed.). 65700I (Apr. 9), Orlando, FL. [Online]. Available WWW:

http://vistology.com/papers/VistologySPIE07.pdf.

Wagner, M. 2007. Death threats force designer to cancel etech conference appearance.

Wired. [Online]. Available WWW:

http://www.informationweek.com/blog/main/archives/2007/03/death_threats_f.html.

\section{About the author}

Sam Berner (B.Ed., Dipl. LIS, Postgraduate Diploma in Information Management) is a principal of the company ECognus (Brisbane, Australia). She is a knowledge management consultant, assisting small to medium enterprises to benefit the most from their intellectual assets. ECognus also provides services in the area of tailored software applications and the digitization of business processes.

ISSN 1560-683X

Published by InterWord Communications for Department of Information and Knowledge Management, University of Johannesburg 